\title{
Simulating Direct and Indirect Damages to Commercial Fisheries from Marine Sand Mining: A Case Study in Korea
}

\author{
Tae-goun Kim • Thomas Grigalunas
}

Published online: 25 August 2009

(C) Springer Science+Business Media, LLC 2009

Erratum to: Environmental Management

(2009) 44:566-578

DOI 10.1007/s00267-009-9339-z

The name of author Tae-goun Kim was misspelled in the print and online versions of this article. It is presented correctly here.

The online version of the original article can be found under doi:10.1007/s00267-009-9339-z.

T. $\operatorname{Kim}(\bowtie)$

Department of Agricultural Economics, Mississippi State

University, P.O. Box 5187, Mississippi State, MS 39762, USA

e-mail: kim@agecon.msstate.edu

T. Grigalunas

Department of Environmental and Natural Resource Economics,

University of Rhode Island, Kingston, RI 02881, USA 